\title{
Perspective
}

PERSPECTIVE Actualité en histoire de l'art

Comptes rendus | 2010

\section{Umění české reformace (1380-1620), Kateřina Horníčková, Michal Šroněk éd., (cat. expo., Prague, écuries impériales du château), Prague, Academia, 2010}

Jan Chlíbec

\section{(2) OpenEdition}

Édition électronique

URL : http://journals.openedition.org/perspective/2483

DOI : $10.4000 /$ perspective. 2483

ISSN : 2269-7721

Éditeur

Institut national d'histoire de l'art

Référence électronique

Jan Chlíbec, « Umění české reformace (1380-1620), Kateřina Horničková, Michal Šroněk éd., (cat. expo., Prague, écuries impériales du château), Prague, Academia, 2010 », Perspective [En ligne], Comptes rendus, mis en ligne le 31 juillet 2013, consulté le 01 octobre 2020. URL : http://

journals.openedition.org/perspective/2483; DOI : https://doi.org/10.4000/perspective.2483

Ce document a été généré automatiquement le 1 octobre 2020. 
Umění české reformace (1380-1620), Kateřina Horníčková, Michal Šroněk éd., (cat. expo., Prague, écuries impériales du château), Prague, Academia, 2010

Jan Chlíbec

\section{RÉFÉRENCE}

Umění české reformace (1380-1620), Kateřina Horníčková, Michal Šroněk éd., (cat. expo., Prague, écuries impériales du château), Prague, Academia, 2010. 
1 Le catalogue de l'exposition «L'art de la Réforme Tchèque (1380-1620) », présentée au château de Prague (Écuries impériales) en 2009-2010, livre une vue complexe de la culture artistique à l'époque de la Réforme tchèque sur une période relativement longue. Celle-ci a en effet précédé d'un siècle les autres mouvements de Réforme européens, même si les Églises réformées en pays tchèques ne reçurent leur liberté qu'en 1609 avec la Lettre de Majesté de l'empereur Rodolphe II. L'ouvrage rassemble de nombreuses études chacune accompagnée du catalogue des œuvres afférentes - et, à côté de chapitres

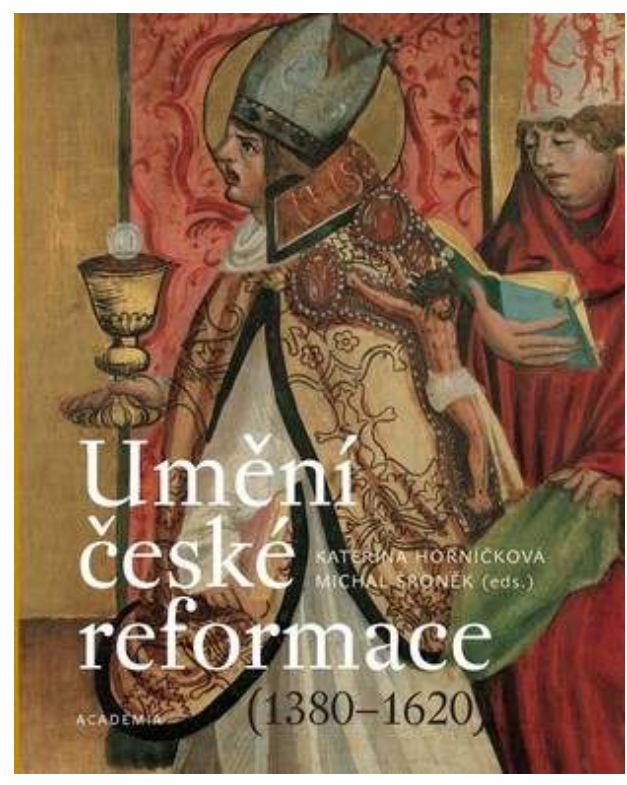
proprement historiques, se focalise notamment sur la façon dont était perçue

l'image au sein des divers courants religieux novateurs. Parmi ces approches, notons ainsi celles qui étudient l'iconoclasme hussite, les liens entre l'utraquisme et l'art, l'Unité des frères et ses relations avec la culture artistique, le livre ou les manuscrits musicaux enluminés de la Réforme tchèque.

2 À ce titre, il faut se souvenir que les œuvres d'art avaient aux yeux des hussites une valeur essentiellement théologique et éthique, leur dimension esthétique étant jugée suspecte, voire dangereuse pour le fidèle. À notre sens, l'exposition ne prenait sans doute pas suffisamment en compte les raisons profondes de l'iconoclasme hussite. L'ouvrage aurait sans doute gagné à replacer ce phénomène dans un contexte international - on pense aux destructions d'œuvres d'art organisées en Italie dans les années 1420 par Bernardin de Sienne, avant le «bûcher des vanités » de Savonarole - et à déterminer ses liens avec des manifestations iconoclastes précédentes telles que la crise byzantine. À l'inverse, les chapitres consacrés à l'Unité des frères (hussisme modéré) et au calvinisme sont beaucoup plus convaincants. 